\title{
Firm Characteristic and Fair Value Adoption in the Measurement of Biological Assets
}

\author{
Tung Dao Nguyen, Van Thi Hong Nguyen
}

\section{ABSTRACT}

\begin{abstract}
Research on how fair value adoption plays an essential role in changing accounting systems in companies. Therefore, this study was conducted to find out the firm characteristics affecting the application of fair value in companies in Vietnam. Statistical analysis technique through a logit model based on 186 companies shows that two business sizes and types of companies impact fair value adoption. In which large-scale companies tend to apply fair value higher than small enterprises. State-owned companies tend to apply fair value higher than joint stock companies operating in the community's interests.
\end{abstract}

Keywords: fair value, fair value adoption, firm characteristics, Vietnam.

\author{
Submitted : November 30, 2021 \\ Published : December 23, 2021 \\ ISSN: 2507-1076 \\ DOI: $10.24018 /$ ejbmr.2021.6.6.1184 \\ Tung Dao Nguyen \\ Academy of Finance, Hanoi, Vietnam. \\ (e-mail: nguyendaotungsci@hvtc.edu.vn) \\ Van Thi Hong Nguyen* \\ Academy of Finance, Hanoi, Vietnam. \\ (e-mail: nguyenhongvan@hvtc.edu.vn) \\ *Corresponding Author
}

\section{INTRODUCTION}

For a developing country like Vietnam, the agricultural sector is still considered an essential industry. According to the General Statistics Office, in 9 months, the GDP of the agriculture, forestry, and fishery industry increased by $2.74 \%$, contributed $23.52 \%$ to the growth of the whole economy, and currently accounts for $12.79 \%$ of the total GDP structure of our entire economy. The GDP of the agricultural sector increased by $3.32 \%$, the forestry sector increased by $3.3 \%$, seafood increased by $0.66 \%$ (GSO, 2021). The agricultural sector not only helps ensure national food security but also makes a significant contribution to exports. In addition, Agriculture is the primary supplier of raw materials for manufacturing and, eventually, rural families that depend on agriculture, accounting for about $80 \%$ of the population (GSO, 2021). Given the importance of the agricultural sector, the Agricultural accounting is becoming more and more important important, along with the current regulation in the agricultural sector of Vietnam, the accounting standard of Agricultural activities needs to be completed soon for international harmonation and lead to convergence with the international accounting standards

There is a major difference in the recognition of organic assets in financial statements prepared under IFRS compared to financial statements prepared under VAS. According to VAS and related regulations, asset items including biological assets are recorded at cost less accumulated amortization (for assets classified as fixed assets) or at net realizable value when it is lower than cost (for assets classified as inventories). Meanwhile, according to International Accounting Standard (IAS) 41 issued in 2001, biological assets for agricultural activities must be recognized at fair value less costs to sell at the reporting date. As accounting for biological assets are new in Vietnam, the preparers of financial statements as well as regulators of IFRS in Vietnam are likely to experience implementation challenges. Therefore, there is a need to investigate the predicaments of the implementation of accounting standard in the agricultural industry in Vietnam in order to develop guidance for effective successful execution

The goal of the study was to uncover the advantages and risks of fair market value reporting for companies in Vietnam's agricultural industry. The study also advocated depicting how $\mathrm{FV}$ affects financial reporting quality in order to increase comparability, relevance and reliability of financial statements. Also, many challenges from appling FV in measuring biological assets. This might propose a platform to reduce the challenges and suggest the road map for IFRS application in near future.

\section{LITERATURE REVIEW}

\section{A. IFRS adoption and financial statements}

In general, IFRS adoption helps enhancing Financial Statement transparency and comparability. Investors would not be confused among conflicted accounting information due to vary accounting standard and regulations of countries. IFRS provides more accurate and more reliable information about the companies in terms of assets, liabilities, revenue, and expenses. Therefore, some investors do not hesitate to invest in companies applied IFRS even though the companies in other countries or other continents.

Tyrall et al. (2007) stated that IFRS application suggest the companies' better access to foreign capital market. However, the legal provisions of each country play an important role in quality improvement of financial statement, even more important than specific regulation in IFRS themselves (Jeanjean and Stolowy, 2008). On the other hand, positive impact of IFRS on debt market was made through capital structure and cost of debts. In term of capital structure, IFRS 
compliance will reduce risk of information asymmetry, facilitating firms (compliance with IFRS) to access foreign loans. Then, the debt/capital ratio will increase.

Investing in global subsidiaries, raising capital from foreign investors, and another global trading would make the number of benefits for those companies. The benefits of the global loan include: (1) Evaluate financial performance compared to international firms (Anderson, 1993); (2) Foreign creditors could indeed assess student loan repayment ability (Jermakowicz, 2004); (3) Evaluate the suitability of foreign suppliers to long-term contracts (Walton, 1992) and whether international customers can continue to place orders and meet credit terms (Anderson, 1993; Jermakowicz, 2004); (4) Evaluate the financial condition and performance of current and prospective partners (Anderson, 1993; Humphry, 1997).

According to PricewaterhouseCoopers (PwC, 2011), businesses and other organizational entities benefit from using IFRS to financial reporting. The adoption will attract a large amount of foreign investment because investors will be assured of the accuracy of financial statements as well as the fairness of the demonstration. Because it has been accepted including over 120 countries, this same adoption of IFRS has gained greater global recognition. It also makes it simple to compare financial data from two or more companies from different countries. PricewaterhouseCoopers' (PwC's) website (PwC, 2011) stated unequivocally the benefits that companies that implement the IFRS would gain. Among the benefits mentioned are: I Financial statement information would be of high quality. This is as a result of lowering the cost of evaluating different investments and trying to improve accounting quality.

Analysts think that analysts who follow companies that use IFRS have more reliable forecasting information than analysts who follow non-IFRS firms. It was suggested that companies that have put in place IFRS often improve in terms of the information reliability and multi comprehensibility (Horton, Serafeim and Serafeim, 2012; Tan, Wang and Welker, 2011).

Tokar (2005) added that for a country that uses a different certificated language than English, translating IFRS into the dominant language is an additional obstacle during the transition period. Furthermore, because IFRS is constantly evolving, application is challenging (Fox et al., 2013). This creates numerous challenges during the gradual transition to full IFRS commemoration (Joshi, Bremser and Al-Ajmi, 2008).

Patel and Heidhues (2008), as well as Wong (2004), have expressed concerns regarding how students learn the International Financial Reporting Requirements (IFRS) and how professionals keep up with changing standards. Another key impediment to the convergence of IFRS with accounting and auditing standards is education, both for experts and nonprofessionals.

Ali and Ustundag (2009) investigated the global development of financial reporting standards as well as their impact in Turkey, a developing nation. The study uncovered various obstacles to IFRS implementation, including the complexities of global standard' structure, possible knowledge gaps, application, and enforcement difficulties.

James (2011) also addressed some substantial and applicable issues that arise when the International Financial Reporting Standards (IFRS) are implemented, particularly in underdeveloped nations where accounting infrastructure is always insufficient. The following issues were discovered throughout the research: I All existing accounting software and information must be modified to allow for the production of accounts in accordance with International Financial Reporting Standards (IFRS); (ii) The cost of educating present employees is quite expensive. This promotes the entity's further development. When IFRS is adopted, personnel usually do not receive adequate training; (iii) the need to educate investors over a considerable period of time before they become familiar with the new standards (James, 2011).

\section{B. Benefits/Challenges of the Fair value in Measuring Biological Assets}

In recent decades, the change of the accounting to FV accountancy has sparked heated discussion. The IASB, one of the most prominent accounting setters and agencies, has pushed for global accounting divergence toward marketbased standards. Despite this tendency toward FV, scholars and practitioners disagree on the benefits and drawbacks of FV accountancy.

Previous empirical research on the value relevance of accountancy data measured at FV are examined. For example, Argilés, Garcia, and Monllau (2011) reviewed the current accounting literature that assesses the value of FV accounting information to investors in academic research using a sample of non-audited accounts of small Spanish agriculture holdings. Furthermore, the financial accounts of agricultural enterprises are now more comparable. 2011 (Argilés, Garcia, and Monllau) Furthermore, the key argument was that establishing a uniform set of standards would improve the comparison of reports produced in various nations but traded on the same marketplace (Whittington, 2005). Users of financial statements would have the same understanding of financial facts given, which would increase worldwide investment. As a result, the IASB created a set of IAS that will produce high-quality financial data to assist participants in the global capital markets in making economic decisions.

Other causes, however, are arguable, and some of these issues are likely to have an impact on agricultural accounting methods. For starters, determining the FV of a biological asset is not always possible. Practitioners' subjective judgments may result in disparities in treatment, obstructing comparability and harmonization. Second, IAS 41 is challenging to apply in a variety of country contexts. Third, annual reassessment of biological assets at $\mathrm{FV}$, particularly in underdeveloped nations, may be complex and costly. Fourth, enterprises' limited usage of net market value measurement reflected a lack of accurate net market value detection information systems.

\section{METHOD}

\section{A. Design}

Based on a theoretical basis, the questionnaire is designed based on basic information of the surveyed companies (independent variables of firm characteristic) such as gender of CEO, firm size, type of ownership, foreign capital in the 
company. The questions are in the form of nominal and hierarchical scales used with independent variables. For the dependent variable is ready to apply FV measured through the binary variable $0-1$. With 1 is ready to apply; 0 - not available to apply. Firms with different characteristics may make decisions about adopting different FV options (Jung et al., 2013). Therefore, the research model based on company characteristics to predict $\mathrm{FV}$ adoption is given as follows:

Firm decicion_F $V_{i}=\alpha+\beta$ Firm characteristic $_{i}+\varepsilon_{i}$

In which the variable is explain in Table I.

\begin{tabular}{|c|c|}
\hline Variables & Code \\
\hline \multicolumn{2}{|r|}{ Dependent variable } \\
\hline Firm decicion_FV & $\begin{aligned} & =1 \text { if Adop } \\
= & 0 \text { if No Adopt }\end{aligned}$ \\
\hline \multicolumn{2}{|r|}{ Independent variables } \\
\hline GENDER & $\begin{array}{c}=1 \text { if CEO is Male } \\
=0 \text { if CEO is Female } \\
=1 \text { if firm size is Lager }\end{array}$ \\
\hline SIZE & $\begin{array}{c}=2 \text { if firm size is Medium } \\
=3 \text { if firm size is Small } \\
=1 \text { if State }\end{array}$ \\
\hline OWNERSHIP & $\begin{array}{c}=2 \text { if Company with non public interest } \\
=3 \text { Company with public interest } \\
=4 \text { if Limited company and private } \\
\text { enterprise }\end{array}$ \\
\hline FOREIGN & $\begin{array}{l}=1 \text { if capital has foreign direct investment } \\
\text { (FDI) } \\
=0 \text { if capital has no FDI }\end{array}$ \\
\hline
\end{tabular}

\section{B. Data Collection}

Data was gathered directly from the accountants of enterprises in the Vietnamese agricultural sector. The directors and accountant were also directly polled for information. The data was collected via self-administered surveys. The information gathered was consistent with the benefits and problems of implementing fair value in Vietnam's agricultural industry. Each element of the sample was examined and edited for the data collected. A total of 186 people were considered for the study. The data can be organized and processed for analysis using the STATA software.

\section{Data Analysis}

With the dependent variable in binary form $0-1$, the logit model is used to analyze this study. With cross-sectional data, the logit model will be analyzed with tests of the model's fit and the accuracy of the logit model's predictive ability.

The probability that an event will happen, denoted by POdds is the ratio between two probabilities: the occurrence of the event and the non-occurrence of it.

When we have the dependent variable, there are only two choices: $\mathrm{Y}=1, \mathrm{Y}=0$ and the probability that that event happens is denoted by $\mathrm{P}(\mathrm{Y}=1)=\mathrm{P}$. Statisticians often use a proxy. The familiar quantity is the Odds of the event happening, not the probability of the event happening, and the Odds are calculated as follows:

$$
\text { Odds }=\frac{P}{1-P}
$$

Thus, according to this formula, Odds is a function of $\mathrm{P}$. Odss $>=0$ and Odds will be undefined when $\mathrm{P}=1$.

$$
P=\frac{O d d s}{O d d s+1}
$$

Thus, the probability $\mathrm{P}$ is a function of Odds.

We have $\mathrm{P}$ is the probability of the event occurring, then (1 - P) is the probability that the event will not occur, the probability $\mathrm{P}$ is measured as follows:

$$
P_{i}=\frac{1}{1+e^{-Z_{i}}}=\frac{1}{1+e^{-\left(\beta_{0}+\beta_{1} X_{1}+\beta_{2} X_{2}+\ldots+\beta_{k} X_{k}\right)}}
$$

With $Z=\beta_{0}+\beta_{1} X_{1}+\beta_{2} X_{2}+\ldots+\beta_{k} X_{k}$

$$
\begin{gathered}
Z_{i} \in(-\infty,+\infty), \quad P_{i} \in(0,1) \quad X_{i}(i=\overline{1, k}) \\
\text { Odds }=\frac{P_{i}}{1-P_{i}}=\frac{1+e^{z_{i}}}{1+e^{-z_{i}}}=e^{z_{i}}
\end{gathered}
$$

Taking the loga nepe of Odds, we have the Logit regression model function:

$$
L_{i}=\ln \left(\frac{P_{i}}{1-P_{i}}\right)=Z_{i}=\beta_{0}+\beta_{1} X_{1}+\beta_{2} X_{2}+\ldots+\beta_{k} X_{k}
$$

with $X_{i}(i=\overline{1, k})$ : independent variables.

\section{RESUlTS}

\section{A. Descriptive}

The results describe companies participating in the survey with 87 companies not ready to apply $(46.77 \%)$ and 99 companies ready to apply $(53.23 \%)$. The gender of the CEO is female, accounting for a larger proportion than male (108 female and 78 male). In terms of scale, the number of medium-sized companies accounted for the majority with 84 companies, accounting for $20.97 \%$; small-scale companies account for 63 companies (accounting for 33.87\%). Large companies with 39 companies accounted for $20.97 \%$. The number of foreign-invested companies is 15 , accounting for $8.11 \%, 170$ companies without foreign investment capital $(91.89 \%)$. In terms of ownership rate, the number of private companies accounts for a large proportion, with 99 companies accounting for $53.23 \%$, state companies accounting for 30 companies accounting for $16.13 \%$.

\begin{tabular}{cccc}
\multicolumn{4}{c}{ TABLE II: THE INFORMATION OF COMPANIES } \\
\hline & & Frequency & Percent \\
\hline \multirow{2}{*}{ Adopt } & No Adopt & 87 & 46.77 \\
& Adopt & 99 & 53.23 \\
& Female & 108 & 58.06 \\
gender & Male & 78 & 41.94 \\
& Large & 39 & 20.97 \\
SIZE & Medium & 84 & 45.16 \\
& Small & 63 & 33.87 \\
& State & 30 & 16.13 \\
Ownership & jsc_not & 42 & 22.58 \\
& jsc_licc & 15 & 8.06 \\
& private & 99 & 53.23 \\
Foreign capital & No & 170 & 91.89 \\
& Foreign capital & 15 & 8.11 \\
\hline N=186 & & & \\
\hline
\end{tabular}




\section{B. Result of Logit Model}

The results of the Logit model analysis show that the factors of business size and type of ownership have an impact on the willingness to apply FV in companies (p-value có ý nghĩa ở 10\%). In which, small-scale companies tend to apply lower than large companies. In other words, large companies tend to be more willing to adapt than small company. In addition, joint-stock companies that have not been classified as public interest companies tend to be less ready to apply than state-owned companies.

TABLE III: THE RESULT OF LOGIT MODEL

\begin{tabular}{ccccc}
\hline Adopt & Coef. & Std. Err. & $\mathrm{z}$ & p-value \\
\hline GENDER & -0.1911329 & 0.3284721 & -0.58 & 0.561 \\
Medium & -0.4876044 & 0.4757833 & -1.02 & 0.305 \\
SIZEall & -0.8941521 & 0.5063632 & -1.77 & 0.077 \\
OWNERSHIP & & & & \\
non-public interest & -0.9351767 & 0.5602579 & -1.67 & 0.095 \\
private & 0.3780941 & 0.4451547 & 0.85 & 0.396 \\
Foreign capital & 1.180765 & 0.8022318 & 1.47 & 0.141 \\
cons & 0.4893763 & 0.4841155 & 1.01 & 0.312 \\
\hline
\end{tabular}

The test of predictive accuracy in the model reached $61.18 \%>50 \%$, so the results can predict well for actual data.

TABLE IV: PREDICTABILITY OF LOGIT MODEL

\begin{tabular}{ccc}
\hline & Forecasting \\
\hline CLASSIFIED & 1 & 0 \\
1 & 57 & 39 \\
0 & 27 & 47 \\
& 84 & 86 \\
\hline CORRECTLY CLASSIFIED & $61.18 \%$ \\
\hline
\end{tabular}

Large companies with large resources and large revenue need professional production and operation processes to solve big problems in the company. Therefore. These large companies are always moving to apply new technologies as well as modern management processes to ensure large workloads. Small businesses tend to be the opposite when the workload is less, leading to the need to convert or adopt the $\mathrm{FV}$ is not urgent. Because when applying, there will be some changes in the structure of the apparatus. This can be an unnecessary trade-off for small businesses. Therefore, in the short term, large companies tend to be more willing to apply FV than small companies.

Next, joint-stock company operating in non-public benefits tend to apply FV lower than state-owned company. This result indicates that state-owned company prefer to apply FV or new processes over joint-stock company operating for the public benefit. With the increasing equitization of stateowned company, a strong innovation has been brought. On the other hand, state-owned joint stock company with private investment will change modern operating methods and working processes. Therefore, applying new models in business activities in general or with FV, in particular, is more focused than in state-owned company.

\section{CONCLUSION}

In the context of the development of the financial system in general, the application of FV is still facing problems with the company's access. Furthermore, different types of businesses have different market approaches, making the application of FV also different. Therefore, this study has helped determine companies' unique characteristics that determine the willingness to apply FV. Research results show that large-size companies have a higher level of willingness to apply FV than small companies. At the same time, stateowned companies have a higher level of willingness to apply than joint-stock companies operating not for the benefit of the community. These results will help the authorities to have appropriate policies in applying FV to companies.

\section{CONFLICT OF INTEREST}

Authors declare that they do not have any conflict of interest.

\section{REFERENCES}

Alp, A., \& Ustundag, S. (2009). Financial reporting transformation: The experience of Turkey. Critical perspectives on Accounting, 20(5), 680699.

Anderson, M. G., Brown, P. F., \& Cores, A. P. (1993). Market Substitution and Copyrights: Predicting Fair Use Case Law. U. Miami Ent. \& Sports L. Rev., 10,33

Argiles, J. M., Garcia-Blandon, J. G., \& Monllau, T. (2011). Fair value versus historic cost-based valuation for biological assets: Predictability of financial information. Spanish Accounting Review.

Fox, A., Hannah, G., Helliar, C., \& Veneziani, M. (2013). The costs and benefits of IFRS implementation in the UK and Italy. Journal of Applied Accounting Research.

GSO. (2021). Announcement of social - economic data for q3/2021

Heidhues, E., \& Patel, C. (2011). IFRS and exercise of accountants' professional judgments: Insights and concerns from a German perspective. Working Paper, Macquarie University.

Horton, J., Serafeim, G., \& Serafeim, I. (2013). Does mandatory IFRS adoption improve the information environment?. Contemporary accounting research, 30(1), 388-423.

James, M. L. (2011). Integrating international financial reporting standards into the accounting curriculum: strategies, benefits and challenges. Academy of Educational Leadership Journal, 15, 127.

Jeanjean, T., \& Stolowy, H. (2008). Do accounting standards matter? An exploratory analysis of earnings management before and after IFRS adoption. Journal of accounting and public policy, 27(6), 480-494.

Jermakowicz, E. K. (2004). Effects of adoption of international financial reporting standards in Belgium: the evidence from BEL-20 companies. Accounting in Europe, 1(1), 51-70.

Joshi, P. L., Bremser, W. G., \& Al-Ajmi, J. (2008). Perceptions of accounting professionals in the adoption and implementation of a single set of global accounting standards: Evidence from Bahrain. Advances in Accounting, 24(1), 41-48.

Jung, B., Pourjalali, H., Wen, E., \& Daniel, S. J. (2013). The association between firm characteristics and CFO's opinions on the fair value option for non-financial assets. Advances in accounting, 29(2), 255266.

Tan, H., Wang, S., \& Welker, M. (2011). Analyst following and forecast accuracy after mandated IFRS adoptions. Journal of accounting research, 49(5), 1307-1357.

Tokar, M. (2005). Convergence and the implementation of a single set of global standards: the real-life challenge. Accounting in Europe, 2(1), 47-68.

Tyrall et al (2007). The Relevance of international financial reporting standards to a developing country: evidence from Kazakhstan. The International Journal of Accounting 42(1):82-110.

Walton, P. J. (Ed.). (2007). The Routledge companion to fair value and financial reporting. London: Routledge.

Whittington, G. (2005). The adoption of international accounting standards in the European Union. European accounting review, 14(1), 127-153. 